Review

\title{
Biological Functions of Thyroid Hormone in Placenta
}

\section{Cheng-Yi Chen ${ }^{1}$, Chie-Pein Chen ${ }^{1,2}$ and Kwang-Huei Lin ${ }^{3, *}$}

1 Department of Medical Research, Mackay Memorial Hospital, Taipei 251, Taiwan;

E-Mails: csmc8972@hotmail.com (C.-Y.C.); cpchen@mmh.org.tw (C.-P.C.)

2 Division of High Risk Pregnancy, Mackay Memorial Hospital, Taipei 104, Taiwan

3 Department of Biochemistry, School of Medicine, Chang-Gung University, Taoyuan 333, Taiwan

* Author to whom correspondence should be addressed; E-Mail: khlin@mail.cgu.edu.tw;

Tel./Fax: +886-3-2118263.

Received: 3 November 2014 / Accepted: 4 February 2015/ Published: 16 February 2015

\begin{abstract}
The thyroid hormone, 3,3,5-triiodo-L-thyronine ( $\left.\mathrm{T}_{3}\right)$, modulates several physiological processes, including cellular growth, differentiation, metabolism, inflammation and proliferation, via interactions with thyroid hormone response elements (TREs) in the regulatory regions of target genes. Infection and inflammation are critical processes in placental development and pregnancy-related diseases. In particular, infection is the leading cause of neonatal mortality and morbidity worldwide. However, to date, no successful approach has been developed for the effective diagnosis of infection in preterm infants. Pre-eclampsia (PE) is a serious disorder that adversely affects $\sim 5 \%$ of human pregnancies. Recent studies identified a multiprotein complex, the inflammasome, including the Nod-like receptor (NLR) family of cytosolic pattern recognition receptors, the adaptor protein apoptosis-associated speck-like protein containing a caspase recruitment domain (ASC) and caspase-1, which plays a vital role in the placenta. The thyroid hormone modulates inflammation processes and is additionally implicated in placental development and disease. Therefore, elucidation of thyroid hormone receptor-regulated inflammation-related molecules, and their underlying mechanisms in placenta, should facilitate the identification of novel predictive and therapeutic targets for placental disorders. This review provides a detailed summary of current knowledge with respect to identification of useful biomarkers and their physiological significance in placenta.
\end{abstract}


Keywords: thyroid hormone receptor; infection; inflammasome; proteomics; placenta

\section{Introduction}

Pioneering proteomic approaches have been continually developed over several decades. Numerous technologies aimed at investigating protein-level regulation have been established, including one-dimensional SDS-PAGE, two-dimensional gel-electrophoresis, differential in-gel electrophoresis (DIGE), isotope-coded affinity tags (ICAT), isobaric tags for relative and absolute quantification (iTRAQ), and stable isotope labeling with amino acid in cell culture (SILAC) [1,2]. Recently, the global proteomics approach was successfully applied to the systemic investigation of the regulatory proteins of tumor-associated genes [3-5], biomarkers for pregnancy and inflammation-associated factors [6-8]. Furthermore, quantitative proteomic approaches have been utilized extensively in various biological fields, such as cancer biology, protein profiling, biomarker identification and quantification, and inflammasome regulation [9-12].

Transthyretin identified as a thyroid hormone-binding protein was discovered in human cerebrospinal fluid and serum [13]. Schreiber et al. [14] demonstrated that transthyretin is a typical negative acute-phase plasma protein, and the expression level was decreased following trauma, surgery and inflammation in liver and blood. Dickson et al. [14] proposed that when the body is in trauma or under inflammatory conditions, the transthyretin transcription rates in the choroid plexus would protect the brain against hypothyroidism. Transthyretin synthesis has been identified in various organs such as liver, choroid plexus of brain and placenta. Transthyretin synthesis is implicated in transporting thyroid hormones (THs) in the brain, and brain development depends on the effects of THs [15]. Furthermore, Roef et al. [16] reported the ratio of free T3-to-free T4 is positively associated with the adiposity-related inflammation markers interleukin- 6 and C-reactive protein, and concluded that the higher ratio of free T3 to free T4 is consistently associated with numerous markers of adverse metabolic profile and cardiovascular risk. Therefore, we speculate that the thyroid hormone may play a role in inflammation processes. Here, we provide a detailed overview of the known regulatory processes of inflammation-related proteins and their physiological significance.

\section{The Relationship between Inflammatory Processes and Placental Disorders}

The immune system plays a crucial role in regulating the processes of both term and preterm labor characterized by altering pro-inflammatory cytokines significantly in gestational tissues $[17,18]$. Romero et al. [19] displayed several factors such as uteroplacental ischemia, cervical disease, decidual hemorrhage, stress, infection, and inflammation involved in the initiation of prematurity. Labor-associated inflammatory cytokines are characterized by immunocyte infiltration and the expression of tumor necrosis factor (TNF)- $\alpha$, interleukin (IL)-1 $\beta$, IL-6, IL-8, and monocyte chemoattractant protein (MCP)-1 in the fetal membranes, cervix, amniotic fluid, and placenta are elevated. Expression of pro-inflammatory mediators resulted in (i) increases in prostaglandins, which promote uterine contractility; (ii) degradation of the chorioamnion extracellular matrix; and (iii) ripening of the cervix matrix metalloproteinases and reduced expression of tissue metalloproteinase inhibitors [18]. The 
magnitude of inflammation identified in term labor is commonly thought to be lower than in preterm labor [20]. Goldenberg et al. [21] suggested that the innate immune system plays an important role to trigger pro-inflammatory signaling in response to injury or infection in the premature initiation of labor. Infection is most commonly identified in the earliest preterm labors, those occurring before 28 weeks of gestation. Goldenberg and colleagues reported that $25 \%-40 \%$ of preterm deliveries resulted from intrauterine infection [21].

Previously, scientists have clarified that pre-eclampsia is a placental pathology with insufficient uteroplacental circulation leading to placental oxidative stress, hypoxia and infarction [22,23]. Redman et al. [24] proposed that pre-eclampsia develops when systemic inflammation, common to all pregnant women in the second half of pregnancy, cause one or other maternal systems to decompensate. Pre-eclampsia exhibits many classical features of inflammation and these are striking in late gestation [24,25]. Several groups have demonstrated a systemic maternal inflammatory response occurs in pre-eclampsia to affect circulating leukocytes. The granulocytes, monocytes and lymphocytes all displayed some degree of activation in pre-eclampsia compared with non-pregnant individuals $[25,26]$. Additionally, several scientists reported circulating pro-inflammatory cytokines are involved in pre-eclampsia. The circulating levels of TNF- $\alpha$, IL- 6 and IL- 8 are significantly elevated in blood [27-30]. Furthermore, Xie et al. [31] reported that expression levels of TLR2, TLR4, IL-1 $\beta$ and NLRP3 are elevated in neutrophils of women with pre-eclampsia compared with normal pregnant women [32]. Recently, the NLRP3 inflammasome was demonstrated to be involved in placenta dysfunction in antiphospholipid syndrome-induced pre-eclampsia . According to these studies, we suggest that preterm labor and pre-eclampsia are inflammatory-associated disorders, and thus discuss these issues here.

\section{Nuclear Receptor Family}

The nuclear receptor (NR) superfamily is a highly conserved and extensively expressed group of ligand-mediated transcription factors in metazoans [33,34]. To date, numerous NRs have been identified in humans and mice, including classical, orphan and adopted orphan receptors [35]. Almost all NRs contain two highly conserved domains: a central DNA-binding domain and ligand-binding domain positioned along the $C$-terminus [36,37]. NRs are activated upon binding to their ligands or undergo ligand-independent activation via post-translational modifications, such as phosphorylation. These receptors mediate specific gene expression by binding to DNA or recruit coregulatory factors to influence various biological processes, including reproduction, metabolism and homeostasis. NRs have been shown to play critical roles, not only in normal homeostatic and metabolic processes, but also diseases, such as inflammation, cancer and obesity [38,39]. Furthermore, Liu et al. [40] used DNA constructs of hormone response elements and mass spectrometry to profile the DNA binding activity of the NR superfamily in mouse liver. Consequently, 35 members of the NR family were detected at the protein level in this study. This approach provides a useful tool to increase coverage of the whole NR proteome for application in studies on DNA binding, cellular translocation and other physiological and pathological conditions, such as inflammation, pregnancy and cancer processes [40]. 


\section{Thyroid Hormone Involvement in Inflammation Processes}

Thyroid hormone receptors (TRs) belong to the superfamily of nuclear hormone receptors that modulate transcription of various genes [41,42]. TH acts as a pleiotropic regulator of growth, differentiation, proliferation and other physiological processes through interactions with thyroid hormone response elements (TREs) located in the regulatory regions of target genes [43] (Figure 1A). Previously, Chang et al. [44] reported that the putative consensus hexamer half-site sequence of TRE is AGGTCA. TREs are arranged as direct repeats (DR), palindromes and inverted palindromes (IP), and vary considerably in terms of nucleotide sequence as well as spacing, number and orientation of half-sites $[41,44]$. Importantly, TH is required to maintain the metabolic rate and oxygen consumption in almost all tissues [37]. TRs contain several domains analogous to other nuclear receptors, including the amino terminal A/B domain, DNA-binding domain (DBD), hinge region containing the nuclear localization signal, and a carboxy-terminal ligand-binding domain (LBD) with specific functions [45-48] (Figure 1B). These receptors interact with the retinoid $\mathrm{X}$ receptor (RXR) to form heterodimers that influence expression of target genes by binding to their TRE regions[49]. Numerous genes, including coagulation factor system components [50], plasma proteins [50,51], nuclear receptor coactivator [52], anti-metastatic proteins [53], proteases [49] oncogenes [5] and inflammatory-associated genes [54], are regulated by thyroid hormone receptors. Proteomic approaches have identified several coregulators that interact with the thyroid hormone receptor, such as steroid receptor coactivator 1-3, thyroid hormone receptor-associated protein 220, Peroxisome Proliferator-activated Receptor- $\gamma$ Coativator-1, Thyroid Hormone Receptor-binding Protein, p300, Androgen Receptor Activator 70, receptor interacting protein 140, dosage-sensitive sex reversal-adrenal hypoplasia congenital critical region of the $\mathrm{X}$ chromosome 1, small heterodimer partner, nuclear receptor corepressor and silencing mediator of retinoid and thyroid hormone receptors [55].

Thyroid hormone levels are associated with major physiological regulatory processes during nutritional adaptation. Recent studies have reported that leptin signaling, mediated by the JAK/STAT pathway, plays a vital role in maintaining TRH, TSH and thyroid hormone expression [56]. Obesity, enhanced by nutrient excess, is characterized by enlarged adipose cells and chronic inflammation [57]. Moreover, hyperleptinemia is reported to increase the index of autoimmune disease via regulation of proinflammatory cytokines and macrophages [58]. Thyroid hormones were linked with obesity more than a century ago, and obesity plays a critical factor in hypothyroidism [59]. Duntas et al. [59] reported that thyroid autoimmunity is highly related with the regulation of inflammasome-related cytokines in obesity [59]. Based on the above evidence, we speculate that inflammation may be regulated through interactions between coregulators and the thyroid hormone receptor. 
(A)

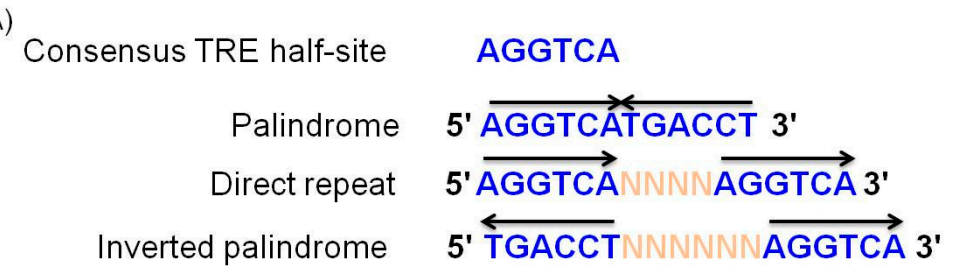

(B)

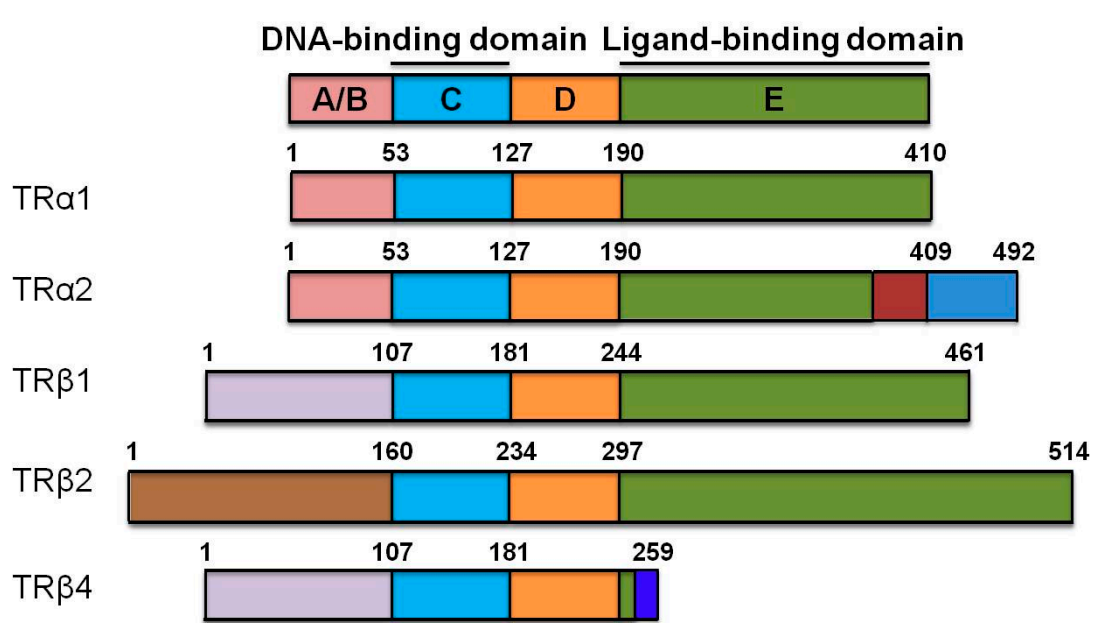

Figure 1. Schematic representation of consensus TRE half-sites and TR $\alpha$ and TR $\beta$ isoforms. (A) The consensus half-site of TRE is divided into palindrome, direct repeat and inverted palindrome sequences. Each half-site presents different orientations and nucleotide spacing (N: nucleotide; arrows: half-site orientation); (B) TR $\alpha 1$ and TR $\beta 1$ are generated by alternative splicing and promoter usage from $\mathrm{TR} \alpha$ and $\mathrm{TR} \beta$. TR isoforms contain several functional domains, including an amino terminal region (A/B domain), conserved DNA-binding domain (DBD) (C domain), hinge region that links the DBD and ligand-binding domains (LBD) (D domain), and LBD responsible for receptor dimerization (E domain). Functional domains with similar amino acid sequences are depicted in the same color.

\section{Thyroid Hormone Is Associated with Placental Development and Disease}

Abnormalities of the maternal thyroid hormone in pregnancy are associated with neurodevelopmental deficiencies in offspring [60,61]. Additionally, $\mathrm{T}_{3}$ and $\mathrm{T}_{4}$ exert effects in several fetal organs, including limbs, brain and liver, from 6-12 weeks of gestation [62]. TH receptors, TH transporters and deiodinase enzymes are expressed in the fetal cerebral cortex at seven weeks gestation. Hence, maternal THs play an essential role in early gestation [63,64]. Maternal $\mathrm{T}_{4}$ crosses the placenta in the first and third trimester of pregnancy. Clinical studies have shown that decreased $\mathrm{TH}$ levels can result in serious adverse effects on intellectual development of fetus [65-67]. Maternally-derived TH, when transported through the placenta, influences neural progenitor proliferation, migration and differentiation within the developing embryo before the onset of endogenous TH production [68,69]. Oki et al. [70] reported the effects of maternal thyroid dysfunction on placental development. Furthermore, THs have been shown to influence villous and extravillous trophoblast proliferation, invasion and viability in vitro [71]. Larijian et al. [72] reported that free T4 and TSH levels were increased significantly in patients with mild pre-eclampsia compared with healthy controls. Furthermore, in severe pre-eclampsia cases, 
the TSH value was higher, but free T3 and free T4 were significantly lower than in controls. The evidence provided a hint that hypofunctioning of the thyroid can result in mild pre-eclampsia and possibly contribute to the pathogenesis. Kumar et al. [73] reported that TSH levels were significantly higher in pre-eclampsia patients compared with controls. However, thyroid hormones values were in the normal range. The TSH titers were over $5 \mathrm{mIU} / \mathrm{mL}$ in about $40 \%$ pre-eclamptic patients in the study group compared with $12.2 \%$ in the controls. Additionally, the T3, free T3 and free T4 levels were lower in preterm infants born to pre-eclamptic mothers with placental insufficiency than preterm infants born to mothers without placental insufficiency. However, the TSH value was higher in preterm infants born to pre-eclamptic mothers with placental insufficiency. Hence, high levels of TSH and low levels of thyroid hormones in cord blood of premature infants born to pre-eclamptic mothers with placental insufficiency imply intrauterine hypothyroidism [73]. Kurlak and co-workers similarly reported lower thyroid hormone levels in pre-eclampsia pregnancy cases [74]. Collectively, we speculate that the levels of thyroid hormone or TSH or hypothyroidism may be a factor to influence pre-eclampsia.

\section{Inflammasome Functions in Placental Disease}

The innate immune system is activated under conditions of microbial infection, such as pathogen-associated molecular patterns (PAMP), damage-associated molecular patterns (DAMP), and tissue damage. Macrophages are vital players in the innate defense system. Activated macrophages secrete proteins to influence the immune response and recruit other immune cells to the tissue damaged area of infected sites [75]. Valimaki et al. [76] analyzed the human primary macrophage secretome stimulated with monosodium urate (MSU) using the high-throughput quantitative gel electrophoresis liquid chromatography-mass spectrometry/mass spectrometry (GeLC-MS/MS) approach combining protein separation via SDS-PAGE and identification with liquid chromatography-MS/MS. MSU, a metabolite released by uric acid, acts as an endogenous DAMP molecule [77]. Results based on bioinformatic analyses clearly indicate that MSU stimulates protein secretion via an unconventional mechanism. Several proteins within the secretome are secreted via vesicle-mediated processes, including the pro-inflammatory cytokines IL-18, IL-1 $\beta$, interferon-induced proteins and danger signal proteins. Additionally, active forms of lysosomal proteases belonging to the cathepsin family are secreted after MSU stimulation, and cathepsin activity is essential for MSU-induced unconventional protein secretion. MSU mediates protein secretion via the cathepsin-src-Pyk2-PI3 kinase signal cascade in human macrophages [76]. Cysteinyl aspartate-specific proteases (caspases) play critical roles in inflammation and apoptosis [78]. In humans, 11 members of the caspase family have been identified, which are divided into three phylogenetic groups depending on their function [79]. Aspartate-specific cysteine protease caspase- 1 is activated in the inflammasome-mediated inflammation process, and responsible for the maturation and release of the cytokines IL-1 $\beta$ and IL-18 during infection and inflammation [80]. Lamkaanfi and co-workers applied a proteome-wide gel-free differential peptide sorting methodology to identify novel caspase-1 substrates. Among the 1022 proteins identified, 20 were validated as caspase- 1 substrates for the first time. The results additionally revealed the existence of a nucleotide binding and oligomerization domain-like receptor/caspase-1/caspase-7 cascade in response to microbial stimuli and bacterial infection [81]. 
Proteases are distributed extensively, constituting more than $2 \%$ of the total human genome, and play diverse roles in cellular processes, such as cell death, catabolism and immune function [82,83]. Human caspases (cysteine aspartyl proteases) consist of 12 homodimeric cysteine proteases that cleave various proteins. The human caspase family is divided into three categories based on their sequences and functional similarities. Caspase-1, -4 , and -5 are inflammatory caspases, identified as activators of proinflammatory cytokines [84]. Although caspase-1 is known to be involved in the inflammasome mechanism, the underlying mechanisms by which inflammatory caspases exert their effects are yet to be elucidated [85]. The inflammasome has been recently defined as a multiprotein complex including a Nod-like receptor (NLR) family of cytosolic pattern recognition receptors, the adaptor protein apoptosis-associated speck-like protein containing a caspase recruitment domain (ASC), and caspase-1 [86]. Inflammasomes are activated by damage-associated molecular patterns (DAMPs) and pathogen-associated molecular patterns (PAMPs), such as bacterial toxins, viral DNA and RNA, extracellular ATP and reactive oxygen species (ROS) [87-90]. Inflammasome assembly leads to caspase-1-dependent cleavage and release of proinflammatory cytokines, IL-1 $\beta$ and IL-18 [91] (Figure 2). The substrates of these inflammatory caspases remain to be fully clarified. Agard et al. [92], using a quantitative stable isotope labeling with amino acids in cell culture (SILAC) approach in THP-1 cells, identified 82 putative caspase-1-cleaved products and three putative caspase- 4 substrates, but no substrates for caspase-5 [92]. Since caspase-1 possesses an extensive range of substrates, it may play a more critical role in inflammatory processes than caspases- 4 and -5 in macrophage cells.

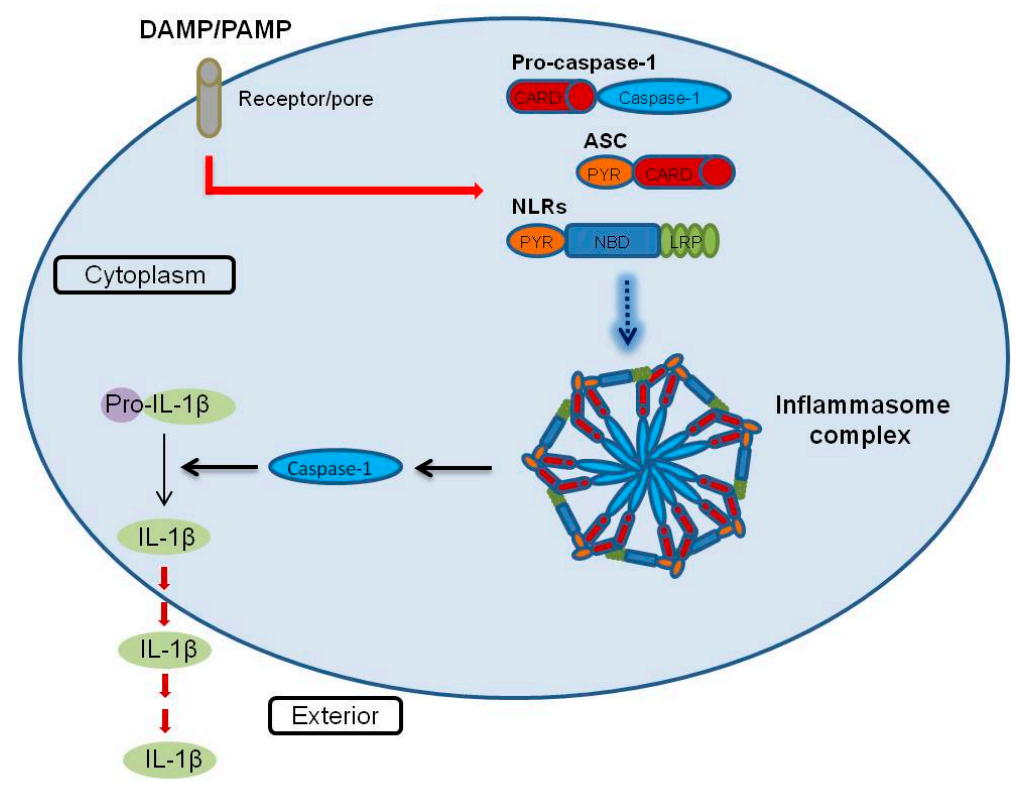

Figure 2. Schematic representation of the inflammasome activation model. Model depicting the regulation of inflammasome activation. Foreign factors, such as DAMP and PAMP, stimulate NLRs, ASC and pro-caspase-1, followed by formation of the inflammasome complex. Subsequently, pro-caspase-1 is cleaved into caspase-1 via activation of the inflammasome complex. Pro-IL- $1 \beta$ is cleaved into mature IL- $1 \beta$ and secreted to the macrophage extracellular matrix. (DAMP: damage-associated molecular patterns, PAMP: pathogen-associated molecular patterns, NLR: Nod-like receptor, ASC: apoptosis-associated speck-like protein containing a caspase recruitment domain, IL-1 $\beta$ : interleukin-1 $\beta$ ). 
Abrahams et al. [93-95] reported that placental trophoblasts express not only Toll-like receptors (TLRs) but also NLRs. Several NLRs and known activators of DAMPs and PAMPs have recently been identified (Table 1). To date, 14 NLR proteins (NLRPs) have been discovered in addition to NOD proteins, and some receptors are activated by infectious stimuli, such as pathogens in trophoblasts [96]. Among the NLRs, Nuclear factor-kappa B (NF- $\kappa \mathrm{B})$ and mitogen-activated protein kinases possess diverse roles and activate different signaling pathways in inflammation processes [97,98]. Clinical studies have demonstrated a significant correlation between placental infection/inflammation and prematurity [99].

Table 1. NLRs-recognized damage-associated molecular pattern DAMP and pathogen-associated molecular patternPAMP.

\begin{tabular}{|c|c|c|}
\hline NLRs & DAMP & PAMP \\
\hline NOD1 & & $\begin{array}{c}\text { Bacterial peptidoglycan, } \\
\gamma \text {-D-glutamyl-meso-diaminopimelic acid }\end{array}$ \\
\hline NOD2 & & Bacterial peptidoglycan, Muramyl dipeptide \\
\hline IPAF & & $\begin{array}{c}\text { Bacterial (Salmonella typhimurium, Pseudomonas } \\
\text { aeruginosa, Legionellapneumophila) }\end{array}$ \\
\hline NALP1 & & Bacterial \\
\hline NALP3 & $\begin{array}{l}\text { Hyaluronan, uric acid crystals, } \\
\text { ATP, silica, asbestos, alum }\end{array}$ & $\begin{array}{l}\text { Bacteria (Staphylococcus aureus, Shigella flexneri), } \\
\text { viruses (Adenovirus, Influenza virus), } \\
\text { fungi (Saccharomyces cerevisiae), } \\
\text { muramyl dipeptide, bacterial pore-forming toxin, } \\
\text { bacteria RNA, malarial crystals }\end{array}$ \\
\hline
\end{tabular}

The inflammasome plays a vital role in both macrophage immunity and cancer cell progression $[8,80]$. Wang et al. [8] systematically investigated the interactome components of inflammasomes in nasopharyngeal carcinoma using the iTRAQ quantitative assay. Using this method, 172 non-redundant proteins were identified in the inflammasome-interacting complex of HK1/ASC cells. Within the interactome profile, the end-binding protein 1 (EB1) is crucial for stimulating the inflammasome via direct interactions with AIM2 and ASC, both in vitro and in vivo [8]. EB1 is an adenomatous polyposis coli (APC)-binding protein that regulates microtubule polymerization [100]. Several studies have demonstrated crucial roles of EB1 in biological processes, such as mitosis and signal transduction [101,102]. Furthermore, numerous microtubule-associated proteins are highly expressed during macrophage activation [103]. Based on these findings, microtubule-associated proteins are proposed to play a role in pre-activation or stabilization of the inflammasome [104].

Pre-eclampsia (PE) is a serious disorder that adversely affects $\sim 5 \%$ human pregnancies. No useful biomarkers or approaches are currently available to identify and treat pre-eclampsia [105]. Subgroup classification is an effective approach to improve the accuracy of predictions for pregnancy outcomes to individualize breast cancer prognosis and treatment [106]. Clinically, gestational hypertension and proteinuria are the basis of the diagnosis in pre-eclampsia [107]. Cox et al. [108] used the shotgun proteomics approach to identify biomarkers of pre-eclampsia with diverse subgroups from plasma membrane proteins at the blood interfaces. In total, 1181 plasma membrane proteins were identified, among which 171 were highly expressed at the maternal blood-trophoblast interface and 192 at the fetal 
endothelial interface. Various genes from distinct subgroups were enriched. The finding that clinically similar pre-eclampsia patients display distinct gene expression profiles in the placenta implies the existence of divergent molecular mechanisms in pre-eclampsia [108].

A considerable number $(12.3 \%)$ of live pregnancies are influenced by preterm delivery in the US, which is a main risk of neonatal mortality and morbidity and a considerable burden on the healthcare system [109]. Infection is common and a leading cause of neonatal mortality and morbidity worldwide [110,111]. A significant clinical correlation between infection and preterm labor has been demonstrated, especially for infants delivered before 30 weeks [112]. Several studies have demonstrated that numerous pro-inflammatory genes are up-regulated in both myometrium [113,114] and fetal membrane $[115,116]$ with labor onset. The inflammatory cells enter the uterus and elevate levels of pro-inflammatory cytokines in the parturition process with both preterm and term labor [117]. The expression levels of TNF- $\alpha$, IL-1 $\beta$, IL-6 are increased in amniotic fluid [118,119]; furthermore IL-1 $\beta$ and IL-6 expression are elevated in the myometrium [120], amnion [121] and choriodecidua [121]. $\mathrm{NF}-\kappa \mathrm{B}$ is an inflammatory-associated transcription factor, which is activated in response to infection and pro-inflammatory cytokines induced in labor. Numerous labor-associated and pro-inflammatory genes are influenced by NF- $\mathrm{BB}$, and aberrant NF- $\mathrm{BB}$ activity can result in a series of inflammatory-related disorders [122,123]. Moreover, scientists have reported the p65 expression level is elevated in both nuclear and cytosolic fractions in fundal uterine segment myometrium in human labor [124]. Stjernholm-Vladic et al. [125] reported that NF- $\kappa \mathrm{B}$ expression in the nucleus is increased at parturition in the cervix. Additionally, NF- $\mathrm{BB}$ DNA binding activity in the amnion is regulated by IL- $1 \beta$ such as p50/p65 heterodimer, p50 and p65 homodimers [126]. Allport et al. [127] reported that the DNA binding and transcriptional activities of $\mathrm{NF}-\kappa \mathrm{B}$ are elevated in amnion cells following spontaneous labor compared with amnion cells at term, suggesting that in labor, NF- $\mathrm{B}$ possesses a critical role in the amnion. Take together, we speculate that NF- $\mathrm{B}$ signaling pathway play a vital role in placental development, inflammation and the parturition processes both in term, and preterm labor.

Diagnosis of infection in preterm infants is extremely difficult. Clinical diagnosis is based on a number of non-specific characteristics, such as difficulty in breathing, unstable temperature and heart rate, and jaundice $[128,129]$. Therefore, a rapid and reliable diagnostic test is essential for the clinical identification of neonatal infection. Kingsmore et al. [7] used immunoassay arrays to detect 142 cytokines in neonatal serum. Eight serum proteins associated with inflammation, fibrinolysis and coagulation were markedly elevated in infected neonates, including interleukin 18, interleukin 2 soluble receptor $\alpha$, P- and E-selectins, neutrophil elastase, C-reactive protein, urokinase plasminogen activator and its cognate receptor. Multiplexed immunoassays of the serum biomarker panel have utility for rapid diagnosis and improve the diagnostic performance for neonatal infection [7].

Amniotic fluid (AF) is a complex and dynamic biological fluid that provides nutrients and protection required for fetal growth. Hence, qualitative and quantitative integrity of AF is essential for normal fetal development during gestation. Free diffusion occurs between the fetus and the AF through fetal skin, placenta and the umbilical cord at 10 to 20 weeks gestation [130]. Therefore, analysis of AF components before skin keratinization that occurs between 19 and 20 weeks of gestation may provide critical information for predicting the physiological and pathological status of the fetus. Cho and co-workers [6] investigated the complexity of AF using three differential fractionation approaches to increase coverage, specifically, two-dimensional LC-MS/MS as well as LC-SDS-PAGE-LC-MS/MS platforms. Based on 
these methods, 842 non-redundant proteins were identified in the AF proteome. Within the AF proteome, biomarkers from several categories have been identified, including intra-amniotic infection, preterm delivery and chromosomal anomalies of the fetus. These findings provide clues that aid in determining the capability of amniotic fluid and detection of significant biomarkers for prenatal diagnosis of fetal abnormalities.

\section{Conclusions}

The thyroid hormone is implicated in various processes, including cancer biology, lipid metabolism, autophagy and inflammation [37,54,131,132]. Inflammation is a critical cellular process in placental development and pregnancy [133]. To date, no useful approaches have been developed to predict pregnancy complications, such as preterm labor. Diagnosis of infection in preterm infants is complex, and clinical identification of neonatal infection is a difficult process based on nonspecific features, such as jaundice, difficulty in breathing and feeding, and unstable temperature [128,134]. However, several cytokines and chemokines are significantly altered in infected neonates [7]. Furthermore, thyroid hormone plays a role in inflammation, placental development and pregnancy-related diseases [70,72]. The inflammasome is clearly implicated in placental trophoblast activity and pregnancy complications $[96,135]$. In summary, we have provided an overview of several proteomic approaches that may be effectively applied to identify useful biomarkers for the prediction of pregnancy-related diseases and establish specific roles of the thyroid hormone and inflammasome in placenta and pregnancy disorders.

\section{Acknowledgments}

This work was supported by grants from Chang-Gung Memorial Hospital, Taoyuan, Taiwan (CMRPD190401, CMRPD190402, CMRPD190403, CMRPD190404).

\section{Conflicts of Interest}

The authors declare no conflict of interest.

\section{References}

1. Everley, P.A.; Krijgsveld, J.; Zetter, B.R.; Gygi, S.P. Quantitative cancer proteomics: Stable isotope labeling with amino acids in cell culture (SILAC) as a tool for prostate cancer research. Mol. Cell. Proteomics 2004, 3, 729-735.

2. Uitto, P.M.; Lance, B.K.; Wood, G.R.; Sherman, J.; Baker, M.S.; Molloy, M.P. Comparing SILAC and two-dimensional gel electrophoresis image analysis for profiling urokinase plasminogen activator signaling in ovarian cancer cells. J. Proteome Res. 2007, 6, 2105-2112.

3. Planque, C.; Kulasingam, V.; Smith, C.R.; Reckamp, K.; Goodglick, L.; Diamandis, E.P. Identification of five candidate lung cancer biomarkers by proteomics analysis of conditioned media of four lung cancer cell lines. Mol. Cell. Proteomics 2009, 8, 2746-2758. 
4. Gronborg, M.; Kristiansen, T.Z.; Iwahori, A.; Chang, R.; Reddy, R.; Sato, N.; Molina, H.; Jensen, O.N.; Hruban, R.H.; Goggins, M.G.; et al. Biomarker discovery from pancreatic cancer secretome using a differential proteomic approach. Mol. Cell. Proteomics 2006, 5, 157-171.

5. Chen, C.Y.; Chi, L.M.; Chi, H.C.; Tsai, M.M.; Tsai, C.Y.; Tseng, Y.H.; Lin, Y.H.; Chen, W.J.; Huang, Y.H.; Lin, K.H. Stable isotope labeling with amino acids in cell culture (SILAC)-based quantitative proteomics study of a thyroid hormone-regulated secretome in human hepatoma cells. Mol. Cell. Proteomics 2012, 11, doi:10.1074/mcp.M111.011270.

6. Cho, C.K.; Shan, S.J.; Winsor, E.J.; Diamandis, E.P. Proteomics analysis of human amniotic fluid. Mol. Cell. Proteomics 2007, 6, 1406-1415.

7. Kingsmore, S.F.; Kennedy, N.; Halliday, H.L.; van Velkinburgh, J.C.; Zhong, S.; Gabriel, V.; Grant, J.; Beavis, W.D.; Tchernev, V.T.; Perlee, L.; et al. Identification of diagnostic biomarkers for infection in premature neonates. Mol. Cell. Proteomics 2008, 7, 1863-1875.

8. Wang, L.J.; Hsu, C.W.; Chen, C.C.; Liang, Y.; Chen, L.C.; Ojcius, D.M.; Tsang, N.M.; Hsueh, C.; Wu, C.C.; Chang, Y.S. Interactome-wide analysis identifies end-binding protein 1 as a crucial component for the speck-like particle formation of activated absence in melanoma 2 (AIM2) inflammasomes. Mol. Cell. Proteomics 2012, 11, 1230-1244.

9. Saraon, P.; Cretu, D.; Musrap, N.; Karagiannis, G.S.; Batruch, I.; Drabovich, A.P.; van der Kwast, T.; Mizokami, A.; Morrissey, C.; Jarvi, K.; et al. Quantitative proteomics reveals that enzymes of the ketogenic pathway are associated with prostate cancer progression. Mol. Cell. Proteomics 2013, 12, 1589-15601.

10. Chen, R.; Pan, S.; Brentnall, T.A.; Aebersold, R. Proteomic profiling of pancreatic cancer for biomarker discovery. Mol. Cell. Proteomics 2005, 4, 523-533.

11. Andreyev, A.Y.; Shen, Z.; Guan, Z.; Ryan, A.; Fahy, E.; Subramaniam, S.; Raetz, C.R.; Briggs, S.; Dennis, E.A. Application of proteomic marker ensembles to subcellular organelle identification. Mol. Cell. Proteomics 2010, 9, 388-402.

12. Bell, C.; English, L.; Boulais, J.; Chemali, M.; Caron-Lizotte, O.; Desjardins, M.; Thibault, P. Quantitative proteomics reveals the induction of mitophagy in tumor necrosis factor- $\alpha$-activated (TNF $\alpha$ ) macrophages. Mol. Cell. Proteomics 2013, 12, 2394-2407.

13. Ingbar, S.H. Pre-albumin: A thyroxinebinding protein of human plasma. Endocrinology 1958, 63, $256-259$.

14. Richardson, S.J. Evolutionary changes to transthyretin: Evolution of transthyretin biosynthesis. FEBS J. 2009, 276, 5342-5356.

15. Dickson, P.W.; Aldred, A.R.; Marley, P.D.; Bannister, D.; Schreiber, G. Rat choroid plexus specializes in the synthesis and the secretion of transthyretin (prealbumin). Regulation of transthyretin synthesis in choroid plexus is independent from that in liver. J. Biol. Chem. 1986, 261, 3475-3478.

16. Roef, G.L.; Rietzschel, E.R.; van Daele, C.M.; Taes, Y.E.; de Buyzere, M.L.; Gillebert, T.C.; Kaufman, J.M. Triiodothyronine and free thyroxine levels are differentially associated with metabolic profile and adiposity-related cardiovascular risk markers in euthyroid middle-aged subjects. Thyroid 2014, 24, 223-231. 
17. Rinaldi, S.F.; Hutchinson, J.L.; Rossi, A.G.; Norman, J.E. Anti-inflammatory mediators as physiological and pharmacological regulators of parturition. Expert Rev. Clin. Immunol. 2011, 7 , 675-696.

18. Challis, J.R.; Lockwood, C.J.; Myatt, L.; Norman, J.E.; Strauss, J.F.; Petraglia, F. Inflammation and Pregnancy. Reprod. Sci. 2009, 16, 206-215.

19. Romero, R.; Espinoza, J.; Kusanovic, J.P.; Gotsch, F.; Hassan, S.; Erez, O.; Chaiworapongsa, T.; Mazor, M. The preterm parturition syndrome. BJOG 2006, 113, 17-42.

20. Gotsch, F.; Romero, R.; Erez, O.; Vaisbuch, E.; Kusanovic, J.P.; Mazaki-Tovi, S.; Kim, S.K.; Hassan, S.; Yeo, L. The preterm parturition syndrome and its implications for understanding the biology, risk assessment, diagnosis, treatment and prevention of preterm birth. J. Matern. Fetal Neonatal Med. 2009, 22, 5-23.

21. Goldenberg, R.L.; Culhane, J.F.; Iams, J.D.; Romero, R. Epidemiology and causes of preterm birth. Lancet 2008, 371, 75-84.

22. Brosens, I.; Renaer, M. On the pathogenesis of placental infarcts in pre-eclampsia. J. Obstet. Gynaecol. Br. Commonw. 1972, 79, 794-799.

23. Pijnenborg, R.; Anthony, J.; Davey, D.A.; Rees, A.; Tiltman, A.; Vercruysse, L.; van Assche, A. Placental bed spiral arteries in the hypertensive disorders of pregnancy. Br. J. Obstet. Gynaecol. 1991, 98, 648-655.

24. Redman, C.W.; Sargent, I.L. Pre-eclampsia, the placenta and the maternal systemic inflammatory response-A review. Placenta 2003, 24, S21-S27.

25. Redman, C.W.; Sacks, G.P.; Sargent, I.L. Preeclampsia: An excessive maternal inflammatory response to pregnancy. Am. J. Obstet. Gynecol. 1999, 180, 499-506.

26. Sacks, G.P.; Studena, K.; Sargent, K.; Redman, C.W. Normal pregnancy and preeclampsia both produce inflammatory changes in peripheral blood leukocytes akin to those of sepsis. Am. J. Obstet. Gynecol. 1998, 179, 80-86.

27. Greer, I.A.; Lyall, F.; Perera, T.; Boswell, F.; Macara, L.M. Increased concentrations of cytokines interleukin-6 and interleukin-1 receptor antagonist in plasma of women with preeclampsia: A mechanism for endothelial dysfunction? Obstet. Gynecol. 1994, 84, 937-940.

28. Vince, G.S.; Starkey, P.M.; Austgulen, R.; Kwiatkowski, D.; Redman, C.W. Interleukin-6, tumour necrosis factor and soluble tumour necrosis factor receptors in women with pre-eclampsia. $B r . J$. Obstet. Gynaecol. 1995, 102, 20-25.

29. Ellis, J.; Wennerholm, U.B.; Bengtsson, A.; Lilja, H.; Pettersson, A.; Sultan, B.; Wennergren, M.; Hagberg, H. Levels of dimethylarginines and cytokines in mild and severe preeclampsia. Acta Obstet. Gynecol. Scand. 2001, 80, 602-608.

30. Benyo, D.F.; Smarason, A.; Redman, C.W.; Sims, C.; Conrad, K.P. Expression of inflammatory cytokines in placentas from women with preeclampsia. J. Clin. Endocrinol. Metab. 2001, 86, 2505-2512.

31. Mulla, M.J.; Salmon, J.E.; Chamley, L.W.; Brosens, J.J.; Boeras, C.M.; Kavathas, P.B.; Abrahams, V.M. A role for uric acid and the Nalp3 inflammasome in antiphospholipid antibody-induced IL-1 $\beta$ production by human first trimester trophoblast. PLoS One 2013, 8, e65237, 
32. Xie, F.; Hu, Y.; Turvey, S.E.; Magee, L.A.; Brunham, R.M.; Choi, K.C.; Krajden, M.; Leung, P.C.; Money, D.M.; Patrick, D.M.; et al. Toll-like receptors 2 and 4 and the cryopyrin inflammasome in normal pregnancy and pre-eclampsia. BJOG 2010, 117, 99-108.

33. Margolis, R.N.; Christakos, S. The nuclear receptor superfamily of steroid hormones and vitamin D gene regulation. An update. Ann. N. Y. Acad. Sci. 2010, 1192, 208-214.

34. Mangelsdorf, D.J.; Thummel, C.; Beato, M.; Herrlich, P.; Schutz, G.; Umesono, K.; Blumberg, B.; Kastner, P.; Mark, M.; Chambon, P.; et al. The nuclear receptor superfamily: The second decade. Cell 1995, 83, 835-859.

35. Zhang, Z.; Burch, P.E.; Cooney, A.J.; Lanz, R.B.; Pereira, F.A.; Wu, J.; Gibbs, R.A.; Weinstock, G.; Wheeler, D.A. Genomic analysis of the nuclear receptor family: New insights into structure, regulation, and evolution from the rat genome. Genome Res. 2004, 14, 580-590.

36. Jin, L.; Li, Y. Structural and functional insights into nuclear receptor signaling. Adv. Drug Deliv. Rev. 2010, 62, 1218-1226.

37. Chen, C.Y.; Tsai, M.M.; Chi, H.C.; Lin, K.H. Biological significance of a thyroid hormone-regulated secretome. Biochim. Biophys. Acta 2013, 1834, 2271-2184.

38. Arrese, M.; Karpen, S.J. Nuclear receptors, inflammation, and liver disease: Insights for cholestatic and fatty liver diseases. Clin. Pharmacol. Ther. 2010, 87, 473-478.

39. Trauner, M.; Halilbasic, E. Nuclear receptors as new perspective for the management of liver diseases. Gastroenterology 2011, 140, 1120-1125.

40. Liu, Q.; Ding, C.; Liu, W.; Song, L.; Liu, M.; Qi, L.; Fu, T.; Malovannaya, A.; Wang, Y.; Qin, J.; et al. In-depth proteomic characterization of endogenous nuclear receptors in mouse liver. Mol. Cell. Proteomics 2013, 12, 473-484.

41. Aranda, A.; Pascual, A. Nuclear hormone receptors and gene expression. Physiol. Rev. 2001, 81, 1269-1304.

42. Walters, M.R.; Nemere, I. Receptors for steroid hormones: Membrane-associated and nuclear forms. Cell. Mol. Life Sci. 2004, 61, 2309-2321.

43. Kim, W.G.; Cheng, S.Y. Thyroid hormone receptors and cancer. Biochim. Biophys. Acta 2012, 1830, 3928-3936.

44. Cheng, S.Y. Multiple mechanisms for regulation of the transcriptional activity of thyroid hormone receptors. Rev. Endocr. Metab. Disord. 2000, 1, 9-18.

45. Izumo, S.; Mahdavi, V. Thyroid hormone receptor $\alpha$ isoforms generated by alternative splicing differentially activate myosin HC gene transcription. Nature 1988, 334, 539-542.

46. Mitsuhashi, T.; Tennyson, G.E.; Nikodem, V.M. Alternative splicing generates messages encoding rat C-ERBA proteins that do not bind thyroid hormone. Proc. Natl. Acad. Sci. USA 1988, $85,5804-5808$.

47. Nakai, A.; Seino, S.; Sakurai, A.; Szilak, I.; Bell, G.I.; DeGroot, L.J. Characterization of a thyroid hormone receptor expressed in human kidney and other tissues. Proc. Natl. Acad. Sci. USA 1988, 85, 2781-2785.

48. Yen, P.M.; Chin, W.W. New advances in understanding the molecular mechanisms of thyroid hormone action. Trends Endocrinol. Metab. 1994, 5, 65-72. 
49. Chen, C.Y.; Chung, I.H.; Tsai, M.M.; Tseng, Y.H.; Chi, H.C.; Tsai, C.Y.; Lin, Y.H.; Wang, Y.C.; Chen, C.P.; $\mathrm{Wu}$, T.I.; et al. Thyroid hormone enhanced human hepatoma cell motility involves brain-specific serine protease 4 activation via ERK signaling. Mol. Cancer 2014, 13, doi:10.1186/1476-4598-13-162.

50. Lin, K.H.; Chen, C.Y.; Chen, S.L.; Yen, C.C.; Huang, Y.H.; Shih, C.H.; Shen, J.J.; Yang, R.C.; Wang, C.S. Regulation of fibronectin by thyroid hormone receptors. J. Mol. Endocrinol. 2004, 33, $445-458$.

51. Lin, K.H.; Lee, H.Y.; Shih, C.H.; Yen, C.C.; Chen, S.L.; Yang, R.C.; Wang, C.S. Plasma protein regulation by thyroid hormone. J. Endocrinol. 2003, 179, 367-377.

52. Tai, P.J.; Huang, Y.H.; Shih, C.H.; Chen, R.N.; Chen, C.D.; Chen, W.J.; Wang, C.S.; Lin, K.H. Direct regulation of androgen receptor-associated protein 70 by thyroid hormone and its receptors. Endocrinology 2007, 148, 3485-3495.

53. Lin, K.H.; Shieh, H.Y.; Hsu, H.C. Negative regulation of the antimetastatic gene Nm23-H1 by thyroid hormone receptors. Endocrinology 2000, 141, 2540-2547.

54. Kwakkel, J.; Surovtseva, O.V.; de Vries, E.M.; Stap, J.; Fliers, E.; Boelen, A. A novel role for the thyroid hormone-activating enzyme type 2 deiodinase in the inflammatory response of macrophages. Endocrinology 2014, 155, 2725-2734.

55. Moore, J.M.; Guy, R.K. Coregulator interactions with the thyroid hormone receptor. Mol. Cell. Proteomics 2005, 4, 475-482.

56. Flier, J.S.; Harris, M.; Hollenberg, A.N. Leptin, nutrition, and the thyroid: The why, the wherefore, and the wiring. J. Clin. Investig. 2000, 105, 859-861.

57. Konner, A.C.; Bruning, J.C. Toll-like receptors: Linking inflammation to metabolism. Trends Endocrinol. Metab. 2011, 22, 16-23.

58. Fresno, M.; Alvarez, R.; Cuesta, N. Toll-like receptors, inflammation, metabolism and obesity. Arch. Physiol. Biochem. 2011, 117, 151-164.

59. Duntas, L.H.; Biondi, B. The interconnections between obesity, thyroid function, and autoimmunity: The multifold role of leptin. Thyroid 2013, 23, 646-653.

60. Haddow, J.E.; Palomaki, G.E.; Allan, W.C.; Williams, J.R.; Knight, G.J.; Gagnon, J.; O'Heir, C.E.; Mitchell, M.L.; Hermos, R.J.; Waisbren, S.E.; et al. Maternal thyroid deficiency during pregnancy and subsequent neuropsychological development of the child. N. Engl. J. Med. 1999, 341, 549-555.

61. Li, Y.; Shan, Z.; Teng, W.; Yu, X.; Fan, C.; Teng, X.; Guo, R.; Wang, H.; Li, J.; Chen, Y.; et al. Abnormalities of maternal thyroid function during pregnancy affect neuropsychological development of their children at 25-30 months. Clin. Endocrinol. 2010, 72, 825-829.

62. Costa, A.; Arisio, R.; Benedetto, C.; Bertino, E.; Fabris, C.; Giraudi, G.; Marozio, L.; Maula, V.; Pagliano, M.; Testori, O.; et al. Thyroid hormones in tissues from human embryos and fetuses. J. Endocrinol. Investig. 1991, 14, 559-568.

63. Chan, S.; Kachilele, S.; McCabe, C.J.; Tannahill, L.A.; Boelaert, K.; Gittoes, N.J.; Visser, T.J.; Franklyn, J.A.; Kilby, M.D. Early expression of thyroid hormone deiodinases and receptors in human fetal cerebral cortex. Brain Res. Dev. Brain Res. 2002, 138, 109-116. 
64. Chan, S.Y.; Martin-Santos, A.; Loubiere, L.S.; Gonzalez, A.M.; Stieger, B.; Logan, A.; McCabe, C.J.; Franklyn, J.A.; Kilby, M.D. The expression of thyroid hormone transporters in the human fetal cerebral cortex during early development and in N-Tera-2 neurodifferentiation. J. Physiol. 2011, 589, 2827-2845.

65. Fleming, C.E.; Mar, F.M.; Franquinho, F.; Saraiva, M.J.; Sousa, M.M. Transthyretin internalization by sensory neurons is megalin mediated and necessary for its neuritogenic activity. J. Neurosci. 2009, 29, 3220-3322.

66. James, S.R.; Franklyn, J.A.; Kilby, M.D. Placental transport of thyroid hormone. Best Pract. Res. Clin. Endocrinol. Metab. 2007, 21, 253-264.

67. Vulsma, T.; Gons, M.H.; de Vijlder, J.J. Maternal-fetal transfer of thyroxine in congenital hypothyroidism due to a total organification defect or thyroid agenesis. N. Engl. J. Med. 1989, 321, $13-16$.

68. Landers, K.A.; McKinnon, B.D.; Li, H.; Subramaniam, V.N.; Mortimer, R.H.; Richard, K. Carrier-mediated thyroid hormone transport into placenta by placental transthyretin. J. Clin. Endocrinol. Metab. 2009, 94, 2610-2616.

69. Auso, E.; Lavado-Autric, R.; Cuevas, E.; del Rey, F.E.; Morreale De Escobar, G.; Berbel, P. A moderate and transient deficiency of maternal thyroid function at the beginning of fetal neocorticogenesis alters neuronal migration. Endocrinology 2004, 145, 4037-4047.

70. Oki, N.; Matsuo, H.; Nakago, S.; Murakoshi, H.; Laoag-Fernandez, J.B.; Maruo, T. Effects of 3,5,3'-triiodothyronine on the invasive potential and the expression of integrins and matrix metalloproteinases in cultured early placental extravillous trophoblasts. J. Clin. Endocrinol. Metab. 2004, 89, 5213-5221.

71. Barber, K.J.; Franklyn, J.A.; McCabe, C.J.; Khanim, F.L.; Bulmer, J.N.; Whitley, G.S.; Kilby, M.D. The in vitro effects of triiodothyronine on epidermal growth factor-induced trophoblast function. J. Clin. Endocrinol. Metab. 2005, 90, 1655-1661.

72. Larijani, B.; Marsoosi, V.; Aghakhani, S.; Moradi, A.; Hashemipour, S. Thyroid hormone alteration in pre-eclamptic women. Gynecol. Endocrinol. 2004, 18, 97-100.

73. Belet, N.; Imdat, H.; Yanik, F.; Kucukoduk, S. Thyroid function tests in preterm infants born to preeclamptic mothers with placental insufficiency. J. Pediatr. Endocrinol. Metab. 2003, 16, 1131-1135.

74. Kurlak, L.O.; Mistry, H.D.; Kaptein, E.; Visser, T.J.; Broughton Pipkin, F. Thyroid hormones and their placental deiodination in normal and pre-eclamptic pregnancy. Placenta 2013, 34, 395-400.

75. Iwasaki, A.; Medzhitov, R. Regulation of adaptive immunity by the innate immune system. Science 2010, 327, 291-295.

76. Valimaki, E.; Miettinen, J.J.; Lietzen, N.; Matikainen, S.; Nyman, T.A. Monosodium urate activates SRC/PYK2/PI3 kinase and cathepsin dependent unconventional protein secretion from human primary macrophages. Mol. Cell. Proteomics 2013, 12, 749-763.

77. Shi, Y.; Evans, J.E.; Rock, K.L. Molecular identification of a danger signal that alerts the immune system to dying cells. Nature 2003, 425, 516-521.

78. Nicholson, D.W. Caspase structure, proteolytic substrates, and function during apoptotic cell death. Cell Death Differ. 1999, 6, 1028-1042. 
79. Lamkanfi, M.; Declercq, W.; Kalai, M.; Saelens, X.; Vandenabeele, P. Alice in caspase land. A phylogenetic analysis of caspases from worm to man. Cell Death Differ. 2002, 9, 358-361.

80. Chen, L.C.; Wang, L.J.; Tsang, N.M.; Ojcius, D.M.; Chen, C.C.; Ouyang, C.N.; Hsueh, C.; Liang, Y.; Chang, K.P.; Chang, Y.S. Tumour inflammasome-derived IL-1 $\beta$ recruits neutrophils and improves local recurrence-free survival in EBV-induced nasopharyngeal carcinoma. EMBO Mol. Med. 2012, 4, 1276-1293.

81. Lamkanfi, M.; Kanneganti, T.D.; Van Damme, P.; Vanden Berghe, T.; Vanoverberghe, I.; Vandekerckhove, J.; Vandenabeele, P.; Gevaert, K.; Nunez, G. Targeted peptidecentric proteomics reveals caspase-7 as a substrate of the caspase- 1 inflammasomes. Mol. Cell. Proteomics 2008, 7 , 2350-2363.

82. Brasier, A.R. The NF-кB regulatory network. Cardiovasc. Toxicol. 2006, 6, 111-130.

83. Pop, C.; Salvesen, G.S. Human caspases: Activation, specificity, and regulation. J. Biol. Chem. 2009, 284, 21777-21781.

84. Fuentes-Prior, P.; Salvesen, G.S. The protein structures that shape caspase activity, specificity, activation and inhibition. Biochem. J. 2004, 384, 201-232.

85. Petrilli, V.; Dostert, C.; Muruve, D.A.; Tschopp, J. The inflammasome: A danger sensing complex triggering innate immunity. Curr. Opin. Immunol. 2007, 19, 615-622.

86. Strowig, T.; Henao-Mejia, J.; Elinav, E.; Flavell, R. Inflammasomes in health and disease. Nature 2012, 481, 278-286.

87. Kanneganti, T.D.; Ozoren, N.; Body-Malapel, M.; Amer, A.; Park, J.H.; Franchi, L.; Whitfield, J.; Barchet, W.; Colonna, M.; Vandenabeele, P.; et al. Bacterial RNA and small antiviral compounds activate caspase-1 through cryopyrin/Nalp3. Nature 2006, 440, 233-236.

88. Mariathasan, S.; Weiss, D.S.; Newton, K.; McBride, J.; O'Rourke, K.; Roose-Girma, M.; Lee, W.P.; Weinrauch, Y.; Monack, D.M.; Dixit, V.M. Cryopyrin activates the inflammasome in response to toxins and ATP. Nature 2006, 440, 228-232.

89. Martinon, F.; Agostini, L.; Meylan, E.; Tschopp, J. Identification of bacterial muramyl dipeptide as activator of the NALP3/cryopyrin inflammasome. Curr. Biol. 2004, 14, 1929-1934.

90. Zhou, R.; Yazdi, A.S.; Menu, P.; Tschopp, J. A role for mitochondria in NLRP3 inflammasome activation. Nature 2011, 469, 221-225.

91. Mariathasan, S.; Monack, D.M. Inflammasome adaptors and sensors: Intracellular regulators of infection and inflammation. Nat. Rev. Immunol. 2007, 7, 31-40.

92. Agard, N.J.; Maltby, D.; Wells, J.A. Inflammatory stimuli regulate caspase substrate profiles. Mol. Cell. Proteomics 2010, 9, 880-893.

93. Abrahams, V.M. Pattern recognition at the maternal-fetal interface. Immunol. Investig. 2008, 37, 427-447.

94. Costello, M.J.; Joyce, S.K.; Abrahams, V.M. NOD protein expression and function in first trimester trophoblast cells. Am. J. Reprod. Immunol. 2007, 57, 67-80.

95. Mulla, M.J.; Yu, A.G.; Cardenas, I.; Guller, S.; Panda, B.; Abrahams, V.M. Regulation of Nod1 and Nod2 in first trimester trophoblast cells. Am. J. Reprod. Immunol. 2009, 61, 294-302.

96. Abrahams, V.M. The role of the Nod-like receptor family in trophoblast innate immune responses. J. Reprod. Immunol. 2011, 88, 112-117. 
97. Girardin, S.E.; Tournebize, R.; Mavris, M.; Page, A.L.; Li, X.; Stark, G.R.; Bertin, J.; DiStefano, P.S.; Yaniv, M.; Sansonetti, P.J.; et al. CARD4/NOD1 mediates NF- $\kappa$ B and JNK activation by invasive Shigella flexneri. EMBO Rep. 2001, 2, 736-742.

98. Ogura, Y.; Inohara, N.; Benito, A.; Chen, F.F.; Yamaoka, S.; Nunez, G. Nod2, a Nod1/Apaf-1

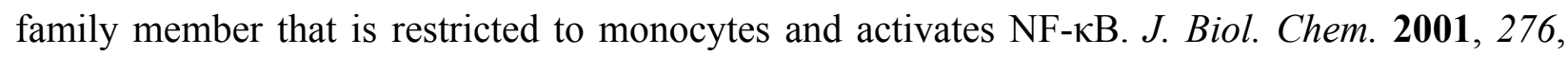
4812-4818.

99. Pettker, C.M.; Buhimschi, I.A.; Magloire, L.K.; Sfakianaki, A.K.; Hamar, B.D.; Buhimschi, C.S. Value of placental microbial evaluation in diagnosing intra-amniotic infection. Obstet. Gynecol. 2007, 109, 739-749.

100. Jiang, K.; Akhmanova, A. Microtubule tip-interacting proteins: A view from both ends. Curr. Opin. Cell Biol. 2011, 23, 94-101.

101. Wen, Y.; Eng, C.H.; Schmoranzer, J.; Cabrera-Poch, N.; Morris, E.J.; Chen, M.; Wallar, B.J.; Alberts, A.S.; Gundersen, G.G. EB1 and APC bind to mDia to stabilize microtubules downstream of Rho and promote cell migration. Nat. Cell Biol. 2004, 6, 820-830.

102. Morrison, E.E. The APC-EB1 interaction. Adv. Exp. Med. Biol. 2009, 656, 41-50.

103. Patel, P.C.; Fisher, K.H.; Yang, E.C.; Deane, C.M.; Harrison, R.E. Proteomic analysis of microtubule-associated proteins during macrophage activation. Mol. Cell. Proteomics 2009, 8, 2500-2514.

104. Dagenais, M.; Skeldon, A.; Saleh, M. The inflammasome: In memory of Dr. Jurg Tschopp. Cell Death Differ. 2012, 19, 5-12.

105. Roberts, J.M.; Cooper, D.W. Pathogenesis and genetics of pre-eclampsia. Lancet 2001, 357, 53-56.

106. Van't Veer, L.J.; Dai, H.; van de Vijver, M.J.; He, Y.D.; Hart, A.A.; Mao, M.; Peterse, H.L.; van der Kooy, K.; Marton, M.J.; Witteveen, A.T.; et al. Gene expression profiling predicts clinical outcome of breast cancer. Nature 2002, 415, 530-536.

107. Sibai, B.M. Diagnosis and management of gestational hypertension and preeclampsia. Obstet. Gynecol. 2003, 102, 181-192.

108. Cox, B.; Sharma, P.; Evangelou, A.I.; Whiteley, K.; Ignatchenko, V.; Ignatchenko, A.; Baczyk, D.; Czikk, M.; Kingdom, J.; Rossant, J.; et al. Translational analysis of mouse and human placental protein and mRNA reveals distinct molecular pathologies in human preeclampsia. Mol. Cell. Proteomics 2011, 10, doi:10.1074/mcp.M111.012526.

109. Martin, J.A.; Osterman, M.J.; Sutton, P.D. Are preterm births on the decline in the United States? Recent data from the National Vital Statistics System; NCHS Data Brief: 2010; pp. 1-8.

110. McGuire, W.; Clerihew, L. Fowlie, P.W. Infection in the preterm infant. BMJ 2004, 329, 1277-1280.

111. Stoll, B.J.; Hansen, N.; Fanaroff, A.A.; Wright, L.L.; Carlo, W.A.; Ehrenkranz, R.A.; Lemons, J.A.; Donovan, E.F.; Stark, A.R.; Tyson, J.E.; et al. Late-onset sepsis in very low birth weight neonates: The experience of the nichd neonatal research network. Pediatrics 2002, 110, 285-291.

112. Lamont, R.F. The role of infection in preterm labour and birth. Hosp. Med. 2003, 64, 644-647. 
113. Chan, E.C.; Fraser, S.; Yin, S.; Yeo, G.; Kwek, K.; Fairclough, R.J.; Smith, R. Human myometrial genes are differentially expressed in labor: A suppression subtractive hybridization study. J. Clin. Endocrinol. Metab. 2002, 87, 2435-2441.

114. Charpigny, G.; Leroy, M.J.; Breuiller-Fouche, M.; Tanfin, Z.; Mhaouty-Kodja, S.; Robin, P.; Leiber, D.; Cohen-Tannoudji, J.; Cabrol, D.; Barberis, C.; et al. A functional genomic study to identify differential gene expression in the preterm and term human myometrium. Biol. Reprod. 2003, 68, 2289-2296.

115. Marvin, K.W.; Keelan, J.A.; Eykholt, R.L.; Sato, T.A.; Mitchell, M.D. Use of cDNA arrays to generate differential expression profiles for inflammatory genes in human gestational membranes delivered at term and preterm. Mol. Hum. Reprod. 2002, 8, 399-408.

116. Bethin, K.E.; Nagai, Y.; Sladek, R.; Asada, M.; Sadovsky, Y.; Hudson, T.J.; Muglia, L.J. Microarray analysis of uterine gene expression in mouse and human pregnancy. Mol. Endocrinol. 2003, 17, 1454-1469.

117. Young, A.; Thomson, A.J.; Ledingham, M.; Jordan, F.; Greer, I.A.; Norman, J.E. Immunolocalization of proinflammatory cytokines in myometrium, cervix, and fetal membranes during human parturition at term. Biol. Reprod. 2002, 66, 445-449.

118. Romero, R.; Yoon, B.H.; Kenney, J.S.; Gomez, R.; Allison, A.C.; Sehgal, P.B. Amniotic fluid interleukin-6 determinations are of diagnostic and prognostic value in preterm labor. Am. J. Reprod. Immunol. 1993, 30, 167-183.

119. Maymon, E.; Ghezzi, F.; Edwin, S.S.; Mazor, M.; Yoon, B.H.; Gomez, R.; Romero, R. The tumor necrosis factor $\alpha$ and its soluble receptor profile in term and preterm parturition. Am. J. Obstet. Gynecol. 1999, 181, 1142-1148.

120. Osman, I.; Young, A.; Ledingham, M.A.; Thomson, A.J.; Jordan, F.; Greer, I.A.; Norman, J.E. Leukocyte density and pro-inflammatory cytokine expression in human fetal membranes, decidua, cervix and myometrium before and during labour at term. Mol. Hum. Reprod. 2003, 9, 41-45.

121. Keelan, J.A.; Marvin, K.W.; Sato, T.A.; Coleman, M.; McCowan, L.M.; Mitchell, M.D. Cytokine abundance in placental tissues: Evidence of inflammatory activation in gestational membranes with term and preterm parturition. Am. J. Obstet. Gynecol. 1999, 181, 1530-1536.

122. Hayden, M.S.; Ghosh, S. Signaling to NF-кB. Genes Dev. 2004, 18, 2195-2224.

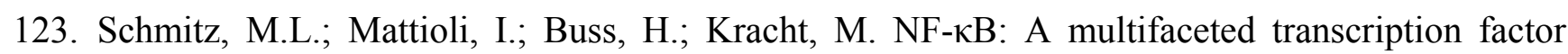
regulated at several levels. Chembiochem 2004, 5, 1348-1358.

124. Lindstrom, T.M.; Bennett, P.R. The role of nuclear factor kappa B in human labour. Reproduction 2005, 130, 569-581.

125. Stjernholm-Vladic, Y.; Stygar, D.; Mansson, C.; Masironi, B.; Akerberg, S.; Wang, H.; Ekman-Ordeberg, G.; Sahlin, L. Factors involved in the inflammatory events of cervical ripening in humans. Reprod. Biol. Endocrinol. 2004, 2, doi:10.1186/1477-7827-2-74.

126. Lee, Y.; Allport, V.; Sykes, A.; Lindstrom, T.; Slater, D.; Bennett, P. The effects of labour and of interleukin $1 \beta$ upon the expression of nuclear factor kappa B related proteins in human amnion. Mol. Hum. Reprod. 2003, 9, 213-218.

127. Allport, V.C.; Pieber, D.; Slater, D.M.; Newton, R.; White, J.O.; Bennett, P.R. Human labour is associated with nuclear factor- $\kappa \mathrm{B}$ activity which mediates cyclo-oxygenase-2 expression and is involved with the "functional progesterone withdrawal". Mol. Hum. Reprod. 2001, 7, 581-586. 
128. Baltimore, R.S. Neonatal sepsis: Epidemiology and management. Paediatr. Drugs 2003, 5, 723-740.

129. Malik, A.; Hui, C.P.; Pennie, R.A.; Kirpalani, H. Beyond the complete blood cell count and C-reactive protein: A systematic review of modern diagnostic tests for neonatal sepsis. Arch. Pediatr. Adolesc. Med. 2003, 157, 511-516.

130. Underwood, M.A.; Gilbert, W.M.; Sherman, M.P. Amniotic fluid: Not just fetal urine anymore. J. Perinatol. 2005, 25, 341-348.

131. Sinha, R.A.; Singh, B.K.; Yen, P.M. Thyroid hormone regulation of hepatic lipid and carbohydrate metabolism. Trends Endocrinol. Metab. 2014, 10, 538-545

132. Tseng, Y.H.; Ke, P.Y.; Liao, C.J.; Wu, S.M.; Chi, H.C.; Tsai, C.Y.; Chen, C.Y.; Lin, Y.H.; Lin, K.H. Chromosome 19 open reading frame 80 is upregulated by thyroid hormone and modulates autophagy and lipid metabolism. Autophagy 2014, 10, 20-31.

133. Chen, C.P.; Chen, Y.Y.; Huang, J.P.; Wu, Y.H.. The effect of conditioned medium derived from human placental multipotent mesenchymal stromal cells on neutrophils: Possible implications for placental infection. Mol. Hum. Reprod. 2014, 20, 1117-1125.

134. Polin, R.A. The "ins and outs" of neonatal sepsis. J. Pediatr. 2003, 143, 3-4.

135. Kavathas, P.B.; Boeras, C.M.; Mulla, M.J.; Abrahams, V.M. Nod1, but not the ASC inflammasome, contributes to induction of IL-1 $\beta$ secretion in human trophoblasts after sensing of Chlamydia trachomatis. Mucosal Immunol. 2013, 6, 235-243.

(C) 2015 by the authors; licensee MDPI, Basel, Switzerland. This article is an open access article distributed under the terms and conditions of the Creative Commons Attribution license (http://creativecommons.org/licenses/by/4.0/). 